\title{
Impasses e desafios para uma avaliação formativa em Programas de Pós-graduação
}

\author{
Impassess and challenges for a formative assessment in \\ post-graduation programs
}

\author{
Maritza Maciel Castrillon MALDONADO' \\ Loriége Pessoa BITENCOURT²
}

\begin{abstract}
Resumo
Este artigo se propóe a pensar impasses e desafios para uma avaliação formativa na pós-graduação. A partir da avaliação quadrienal de Programas de Pós-Graduação em Educação (2013-2016), tomando por base normatizaçôes e limites do documento da Área de Educação - CAPES, da Plataforma Sucupira, e também a realidade do Programa de Pós-Graduação em Educação da UNEMAT - PPGEdu/UNEMAT, cartografam-se alguns impasses e problematizam-se desafios para se constituir uma avaliaçáo mais formativa no quadriênio 2017-2020.
\end{abstract}

Palavras-Chave: Educação. Pós-Graduação. Avaliação Formativa.
Abstract

This article intends thinking on impasses and challenges aiming at a formative assessment in post-graduation programs. From the four-year assessment of Post-Graduation Programs in Education (2013-2016) on the basis of standardizations and limits of the document issued by the Education Sector - CAPES, of Sucupira Platform, and also based on the reality of the Post-Graduation Program in Education of UNEMAT - PPGEdu/UNEMAT, a few impasses are mapped and challenges discussed in order to make a more formative assessment in the four-year period of 2017-2020.

Keywords: Education. Post-Graduation. Formative Assessment.

1 Professora da Universidade do Estado de Mato Grosso - UNEMAT, Coordenadora do Programa de Pós-Graduação em Educação e do Ateliê de Imagem e Educação - AIE/UNEMAT. Pós-Doutora em Educação pela Universidade do Estado do Rio de Janeiro - PROPed/UERJ, doutora em Educação pela Universidade Federal Fluminense e Mestre em educação pela Universidade Federal do Rio Grande do Sul. Atua principalmente nos seguintes temas: Currículo, cinema, infâncias e Educação. E-mail: maritzacmaldonado@gmail.com

2 Professora da Universidade do Estado de Mato Grosso - UNEMAT, Vice-Coordenadora do Programa de Pós-Graduação em Educação - PPGEdu/UNEMAT. Doutora em Educação pela Universidade Federal do Rio Grande do Sul e Mestre em Educação pela Universidade Federal do Mato Grosso. Líder do Grupo de Estudos e Pesquisas Formação e Docência - GFORDOC, do CNPq. Atua principalmente nos seguintes temas: Formação de Professores, Educação Matemática, Docência e Pedagogia Universitária. E-mail: lori. pessoa@hotmail.com

\begin{tabular}{|l|l|l|l|l|l|} 
R. Educ. Públ. & Cuiabá & v. 28 & n. 68 & p. 429-439 & maio/ago. 2019 \\
\hline
\end{tabular}




\section{Introdução}

O ano de 2017 foi o início de um novo ciclo, uma nova fase para os Programas de Pós-Graduação em Educação. Trata-se de um recomeço repleto de novos jogos estratégicos, de açóes e reaçóes, de perguntas e respostas, de dominaçóes e de esquivas, mas, sem dúvida, se inicia aqui, junto a tudo isso, uma grande batalha. Como nos ensina Foucault (2005), em $A$ verdade e as formas jurídicas, existem, em nossas sociedades, vários outros lugares onde a verdade se forma, onde certo número de regras de jogo é definido. Um desses lugares (e aprendemos estando nele) é no espaço-tempo virtual da Plataforma Sucupira. Trata-se de um lugar onde se produz determinada "verdade", com provas, inquéritos e exames que tentam capturar o movimento de quatro anos do espaço-tempo real de Programas de Pós-Graduação em Educação. É preenchendo cuidadosamente um formulário repleto de regras e normas, recheado de conceitos e notas que definimos o que é conhecer, quem conhece e onde se conhece melhor. E o que é conhecer senão entrar em um jogo que nos afasta, cada vez mais, da natureza humana? E nós, imersos nos saberes-poderes que constituem a Plataforma e em Programas de PósGraduação, entrando nesse jogo, o jogamos com as regras das Ciências Humanas; lutamos com as armas da educação! Nós criamos as regras, nós construímos as armas. Nós, os humanos, os educados! Somos nós, que discursamos pela equidade, que garantimos, em critérios quantitativos e excludentes de avaliação presentes na Plataforma e definimos para nossas vidas produtivas, acadêmicas e educativas, regras de desigualdade, de diferenciação, de discrepância, de discriminação, de discernimento, de dessemelhança, de separação. Somos nós, que lutamos tanto pela legitimação da diferença, que nos esforçamos para escrever, na plataforma, ao final de cada ano e de cada quadriênio, a mesmidade de todos nós. Somos nós que lutamos, apesar de nós, e, muitas vezes, contra nós, por notas melhores, qualis maiores, produtividades, eficiências, impactos. É... Parece-nos paradoxal.

Esse prólogo talvez ainda seja resquício do resultado da avaliaçáo quadrienal 2013-2016. Fazê-lo nos apazigua um pouco a alma para tentar traduzir a curta história de vida do Programa de Pós-Graduação em Educação - PPGEdu, Mestrado em Educação, da Universidade do Estado de Mato Grosso "Prof. Carlos Alberto Reyes Maldonado" - UNEMAT. Esse prólogo se fez necessário para tentar nos fazer ouvir de uma maneira distinta. Para tentar nos fazer sentir por nossas diferenças e não pelas identificaçôes que tentam nos capturar. Embora saibamos que, ao preenchermos a Plataforma, "a ordem do discurso" nos impóe formas ritualizadas de seleção, organização e controle (FOUCAULT, 1999), temos o propósito, com este texto, de pensar, apesar dela e de todos os mecanismos de exclusão que a 
compóem, que as singularidades de uma Universidade do interior do Estado de Mato Grosso, que promove ensino, pesquisa e extensáo, produz conhecimento e faz diferença na vida de pessoas, sejam possíveis. A aposta política deste artigo é pensar que a avaliação quadrienal dos Programas de Pós-Graduação em Educação possa ser menos classificatória e excludente e mais formativa e inclusiva.

\section{Impasses sentidos e vividos no quadriênio 2013-2016}

O PPGEdu UNEMAT, semelhante a muitos outros Programas de PósGraduação do país, resiste e persiste em seu princípio ético, político e estético de compromisso social. Está envolvido, entre outras questóes, com intensas atividades de Formação de Professores da cidade e do campo; Formação continuada de educadores do campo; Formaçáo Continuada de professores através do cinema; educação em espaços não escolares; move-se para compreender a abrangência de políticas afirmativas; envolve-se com questóes socioculturais relacionadas à Infância e à Adolescência; movimenta-se entre populações indígenas, quilombolas e ribeirinhas; ouve clamores e cria, coletivamente, alternativas para constituir formas outras de afetos e vidas. O PPGEdu parte do princípio de que a ciência pode classificar e nomear os órgãos de um sabiá, mas não pode medir os seus encantos. A ciência náo pode calcular quantos cavalos de força existem nos encantos de um sabiá. Quem acumula muita informação perde o condão de adivinhar: divinare. Os sabiás divinam (BARROS, 1999, p.53).

$\mathrm{O}$ investimento efetivo em atividades de pesquisa com interface na extensão dos Grupos de Pesquisa do PPGEdu/UNEMAT ocorre no sentido de acreditarmos que classificar, nomear e medir valem menos do que divinar. Partimos do princípio de que temos que criar mecanismos para que o condáo de divinar seja visibilizado na Avaliação Quadrienal, seja sentido (por ser impossível de ser quantificável) na Plataforma Sucupira, e seja mais valorizado em relação aos fatores de impacto, produtividade e qualis.

No entanto, eis que os impasses se constituem:

- Como medir o sorriso da criança do acampamento... quando a professora pesquisadora chega com uma formação continuada, mobiliza a todos e traz consigo esperança de uma outra vida?

- Como classificar a preocupação do barqueiro ao conduzir crianças e professores para a escola, nas curvas do rio Guariba Roosevelt, no Noroeste de Mato Grosso?

- Como dar visibilidade às tentativas de alfabetização das crianças que vivem na fronteira Brasil-Bolívia? 
- Como propiciar encontros formativos a professores indígenas, a partir de seus saberes, para que produzam materiais didático-pedagógicos, tendo como foco letramento e numeramento, sem ser afetado por línguas distintas, hábitos e costumes que não são mais os nossos?

- Como quantificar a importância de açóes de socioeconomia solidária, que coloca o pequeno produtor rural no pátio da Universidade para comercializar seus produtos agroecológicos?

- Como dimensionar um programa de incubadora que visa fortalecer a economia solidária e construir políticas públicas para garantir a sustentabilidade do desenvolvimento de atividades de inclusão socioprodutiva de pessoas em estado de vulnerabilidade social, especificamente catadores de lixo?

A ideia aqui não é reforçar estereótipos que circulam nacionalmente sobre Mato Grosso, ou sobre a regiáo Centro Oeste do Brasil. Até porque, todos sabemos, Mato Grosso, por exemplo, é o terceiro Estado da Federação em extensão territorial. Esse território guarda o terceiro contingente de povos indígenas e dezenas de comunidades quilombolas que ainda lutam pela demarcação e titulação de suas terras. De acordo com o Censo de 2010, mais de $60 \%$ da população mato-grossense é negra. Cabe também registrar que Mato Grosso é o único Estado da Federação com três biomas: pantanal, floresta amazônica e cerrado. Essas características socioambientais têm sido, nos últimos anos, fortemente pressionadas pela expansão da economia produtora/exploradora de commodities, processo este que impede que o Estado saia do mapa da devastação ambiental, dos conflitos agrários e sociais e da explosão dos indicadores de violência no campo e na cidade. Fronteiriço com a Bolívia, Mato Grosso também tem a peculiaridade de pensar suas fronteiras para além da geografia física, o que tem possibilitado a realização de ações multilaterais. As complexas relações sociais (étnicas, raciais, culturais, identitárias, territoriais, internacionais, etc.) encontram terreno fértil nas açōes educacionais/científicas realizadas pelo Programa de Pós-Graduação em Educação que se encontra, concomitantemente, em terreno movediço, pantanoso. Como traduzir a singularidade de projetos, pesquisas, açóes, intervençóes, sujos de mundo, em linguagem quantificável e compreensível na Plataforma Sucupira? Eis o impasse.

Segundo o Documento de Área da CAPES (BRASIL, 2016), a área de Educação definiu para a avaliação quadrienal 2013-2016 a seguinte proporção para os Quesitos a serem analisados:

1. Proposta do Programa;

2. Corpo Docente, $15 \%$; 


\section{Corpo Discente, Teses e Dissertaçóes, 35\%; \\ 4. Produção Intelectual, 35\%; \\ 5. Inserção Social, $15 \%$.}

Em relação à avaliação realizada no triênio anterior, a maior alteração aconteceu no que se refere ao quesito 4, passando a ser considerada a média ponderada de até oito produçóes mais bem qualificadas por docente permanente no quadriênio, compreendendo livros, capítulos, verbetes e periódicos', e náo mais toda a produção apresentada pelos docentes. As pontuaçóes para cada produto serão as mesmas utilizadas na avaliação trienal anterior. $\mathrm{O}$ objetivo é alterar a característica da indução decorrente da avaliação da pós-graduação. $\mathrm{O}$ que se espera não é que simplesmente os programas passem a produzir mais, mas que passem a produzir melhor e isso se reflita nas métricas adotadas no processo de avaliação. Dessa forma, espera-se com essa alteração que pontue mais quem produz melhor e não quem produz mais. (BRASIL, 2016, p. 9, grifo nosso).

É um pouco sobre quem produz melhor que centraremos nossa análise. Para isso, não teríamos como não relacionar o quesito 4, Produção Intelectual, ao quesito 5, Inserção Social. Partimos do princípio de que pesquisas resultante de projetos com inserçáo social demandam um tempo maior para alcançar resultados publicáveis em periódicos qualificados.

Esse tipo de pesquisa requer do pesquisador:

Parar para pensar, para olhar, parar para escutar, pensar mais devagar, olhar mais devagar, escutar mais devagar; parar para sentir, sentir mais devagar, demorar-se nos detalhes; suspender a opinião, suspender o juízo, suspender a vontade, suspender o automatismo da ação, cultivar a atenção e a delicadeza, abrir os olhos e os ouvidos, falar sobre o que nos acontece, aprender a lentidão, escutar os outros, cultivar a arte do encontro, calar muito, ter paciência e dar-se tempo e espaço (LARROSA, 2004, p. 160).

Além do tempo ser outro, geralmente tratam-se de pesquisas menores, realidades diversas, de sujeitos singulares e invisibilizados, oriundas de Programas pequenos, com conceitos menores ainda; o que essas pesquisas têm a dizer, muitas vezes, não interessa às narrativas dominantes, à vontade de verdade que constitui a ordem discursiva hegemônica. Ora não interessa pela não predisposição (de alguns) de interromper a história contínua com fragmentos que podem paralisála, rompê-la em mil pedaços, e ver os cacos saindo (GAGNEBIN, 1993), constituindo novas histórias de lutas, forças e resistências; ora não interessa para não sair do lugar comum, da poltrona de veludo, da mesmidade que define quem são os melhores e relega os outros a serem outros, e só. 
Mas, como produzir o que se espera no quesito Produção Intelectual, que representa 35\% da avaliação na Plataforma Sucupira, que se entende por melhor, estando sujo de mundo, ou realizando pesquisas implicadas com questôes sociais que representam $15 \%$ da mesma Plataforma?

\section{Quantificar qualis na Sucupira e se sujar de mundo, eis o impasse não pensado no documento de área CAPES 2016}

O artigo de Baptista e Silva (2017) nos ajuda a pensar sobre impasses da necessidade de produzir melhor e sujar-se de mundo. Sabemos das redes de saberes-poderes que compóem os critérios para que as revistas sejam bem qualificadas; sabemos também das redes saberes-poderes que compóem os critérios para que o pesquisador tenha seu artigo aprovado e publicado nessas revistas. Essas redes se retroalimentam e alimentam o que se espera na Plataforma Sucupira. Para o pesquisador produzir melhor, precisa, em primeiro lugar, ter um bom projeto. Para esse projeto ser considerado bom, precisa ser aprovado por uma Instituição de Fomento. Para ser aprovado por uma instituição de fomento, esse pesquisador precisa comprovar, em outra Plataforma, a Lattes, que está dentre aqueles que produzem melhor. Aí, esse pesquisador, que já se encontra em um Programa de Pós-Graduação, que já tem um grupo de pesquisa constituído, que já garantiu, em outros espaços e tempos, uma produção melhor qualificada para viabilizar aprovaçáo de seus projetos e garantir suas produçóes em revistas qualificadas, senta-se em sua poltrona de veludo, no céu (aquele lugar reservado aos iluminados) e produz novos projetos, que resultam em mais artigos que são avaliados nas revistas qualificadas e na plataforma Sucupira, como sendo os melhores. Esses pesquisadores, projetos, artigos, Programas, são compreendidos na Sucupira por falarem a mesma linguagem... aquela dos números quantificáveis, provindas daquele mundo ideal, que também fica no céu.

A narrativa do visitante anônimo ao pesquisador, produzida por Baptista e Silva, pode forçar ${ }^{3}$ nosso pensamento a pensar um pouco sobre as condições que possibilitam o produzir melhor:

3 O termo "forçar o pensamento a pensar" é utilizado neste artigo a partir do conceito de Gilles Deleuze que diz que "o que é primeiro no pensamento é o arrombamento, a violência, é o inimigo, e nada supōe a filosofia" (DELEUZE, 1988, p. 230). Assim, forçar o pensamento significa, para o filósofo francês, arrombamento, que leva à criação. 
Entrei pela janela. Você não me conhece. Poderia ter entrado pela fresta da porta, mas a janela entreaberta me seduziu. A casa constantemente fechada me provoca. A ausência de luz solar, ruídos do bairro, sopros de ar nas cortinas me enfurece. A inexistência de cheiros de coisas vivas parece afirmar que a cidade é desprezada por tudo aqui. Desprezo insuportável. As paredes sem poros justificam também minha ira. Não trema. A minha visita poderá ser um perigo para esta fortaleza mofada. Levante. A imobilidade acabou. Não pergunte quem eu sou. Náo responderei de onde vim. Abra as outras janelas. Tristezas, dúvidas, a agonia infinita deste mausoléu serão destruídas. $\mathrm{O}$ conforto da sua arrogante solidão está encerrado. Anos e mais anos da sua vida foram gastos nesta poltrona grudada ao seu traseiro [...] $\mathrm{O}$ mundo visto, interpretado e sentido na poltrona de veludo também me enfurece. Inquietaçóes, angústias imóveis não me comovem [...]. Você agora está em apuros. O tempo sem poros será aniquilado. $\mathrm{O}$ tempo sem relógios, dos calendários, das agendas será destruído implacavelmente [...]. Olhe para frente, preste atenção ao que está fora desta casa [...]. Tire os óculos, abra os olhos, respire profundamente. A caminhada precisará de músculos tesos e olfato apurado. No percurso a morte será encontrada a cada esquina [...]. O cháo, o céu por onde passam as quimeras nesta casa mofada desconhecem a desolação do lado de fora (BAPTISTA; SILVA, 2017, p.156).

O convite do visitante anônimo ao pesquisador, para sair do conforto de sua poltrona de veludo e de sua casa mofada, é traduzido, neste texto, como um convite ao pesquisador para sujar-se de mundo. Sujar-se de mundo, em nosso entendimento, pode ser traduzido na Plataforma Sucupira por Inserção Social, quesito 5 do documento de área da CAPES.

Trata-se de um convite, voltando à narrativa do visitante, para entrar na cidade enrugada, que "o espera com epifanias desconhecidas para seu universo enclausurado" (id ibidem p. 55). Trata-se de um convite para esquecer a casa mofada, escura e fria (pelo efeito do ar-condicionado) e abandonar o conforto da poltrona de veludo em um escritório cheio de livros decorados e decorativos. Trata-se de um convite para desencurvar-se e aventurar-se ao mundo:

Sentir seu cheiro, bom ou ruim para olfato seletivo de quem nunca entrou em um lixáo para selecionar materiais recicláveis;

Ouvir o clamor da criança de quatro anos, na creche, ao dizer que o domingo do dia das mães não é dia das mães, a quem ela tem todos os dias. É o dia de visitar seu pai na cadeia;

Emocionar-se com o adolescente que se encontra no sistema socioeducativo, que diz sentir o que é e constituir-se como "menor infrator" a cada passar de cassetete nas grades que o aprisionam; 
Acompanhar a produção do biscoito de cumbaru, com o cumbaru caído no sítio do seu Zé e trazê-los (o biscoito e o seu Zé) para o pátio da Universidade, comprovando que a socioeconomia solidária é possível;

Desnaturalizar a narrativa de um professor que diz, após a exibição de um filme, que seu aluno gay nasceu com um "problema" que pode ser corrigido;

Conviver com o vai e vem da criança ribeirinha-pantaneira e perceber como seus encontros com o mundo são distintos e diversos do ideal de infância traduzido nos documentos instituídos que dizem o que é viver nessa fase da vida...

Mas a Plataforma não sente cheiros, não ouve clamores, não se emociona, não acompanha, não problematiza, não desnaturaliza, não convive... a Plataforma não se afeta com narrativas como a do Senhor Manoel, carinhosamente chamado de seu Neca, camponês assentado de 52 anos, que concluiu a 4a série primária (como dito por ele), conferencista no VII Encontro Cacerense de Economia Solidária ENCAESES, evento anual que acontece na UNEMAT. Ele foi o protagonista da mesa, ladeado por professores doutores do Rio de Janeiro e do IFMT. Ouçamos o que ele disse:

A economia solidária trouxe pra nós um conhecimento além da renda, da renda financeira. Trouxe pra nós um ensinamento de como a gente faz a produção sem agrotóxicos. Ensinou a gente também a trabalhar no coletivo aqui na roça. Todo mundo junto, trabalhando, alegre, feliz. Trouxe uma alegria e uma ponte que nós precisamos para que nós possa sobreviver da nossa terra, usando nosso próprio trabalho. Ensinou nós a dar valor a nossa mão de obra. Ensinou a colocar valor a nosso produto e ensinou nós também a comercializar. Falando de economia solidária que surgiu pra nós como uma fonte de renda e um ensinamento, nós quer dizer que quem faz parte desse grupo está dentro de uma universidade estudando. Uma universidade aqui na roça, aqui na lavoura. Através da economia solidária nós chegamos na FEISOL. É uma feira que está aqui na UNEMAT, uma feira que a gente tá aqui. Uma feira que pra vocês é uma feira, mas que pra nós é uma festa. Nós agricultor chega na feira, nós troca ideia, nos conversa, nós colhe pensamento, nós recebe informação, nós passa nossas informação também diretamente do produtor e do agricultor que produz ao consumidor que consome. Isto pra nós foi um desenvolvimento muito grande. É por isso que nós tem que agradecer aí o núcleo do UNITRABALHO, os bolsistas e também o coletivo de alunos e professores que trabalham... e hoje estamos com uma cooperativa dentro da agroecologia para termos mais força e poder para preservar a nossa terra, as nossas água e a nossa vida.

Seu Neca é um anônimo que foi afetado por uma pesquisa acontecimento, por pesquisa com inserção social e por pesquisadores ratos e urubus, que náo sobrevoam, como as andorinhas, de cima, a cidade. Que enxergam suas porosidades, que sentem seus cheiros, que produzem de modos distintos. 
Voltemos ao narrador anônimo que entra na casa do pesquisador. Ele diz:

Aprenda a explorar os lugares como os ratos. Andorinhas e ratos exploram cidades de modos diversos. Ratos são atentos aos restos, às migalhas, aos dejetos esquecidos da cidade. Esticam, encolhem, mudam o corpo para explorar as superfícies. Hesitam quando avistam o caminho mais fácil, sentem as rugosidades do chão como indícios de outro percurso. São seres atentos às matérias, ao frescor e ao apodrecimento dos resíduos que os alimentam [...]. Explorar as cidades como andorinhas seria inútil para os errantes que aprendem com a superfície. Do alto desconheceriam os fiapos, os restos, os pedaços de histórias que alimentam e os ensinam a conhecer lugares pelos desvios, buracos, declives, pelo errar. Do alto a cidade não fede. [...]. Aprenda também com os urubus; deles a rota do voo é interrompida pelos cheiros. São os devoradores de carniças que abrem caminhos, facilitam passagens produzidas por acontecimentos. (BAPTISTA; SILVA, 2017, p.156).

Eis que estamos sujos de mundo. De tão sujos que estamos não conseguimos mais encontrar jeito para nos acomodar na poltrona de veludo e produzir conhecimentos que apaziguam a alma de muitos. Eis que paramos para pensar, para olhar, parar para escutar... tudo bem devagar!

Mas a Sucupira tem um tempo que náo é lento e que requer de nós, pesquisadores, produçóes. Não produçôes publicáveis em livros ou jornais de pequena circulação. Requer de nós produçóes melhores, publicadas em periódicos melhores, que sejam citadas e que produzam impacto. Ah, de preferência que sejam internacionais e em língua inglesa. Falaremos agora, um pouco e para finalizar, dos desafios da avaliação formativa da pós-graduação.

\section{Desafios da avaliação formativa na pós-graduação}

Avaliação Formativa? Acreditamos ser necessário, de início, definir os dois termos para, em seguida, abordarmos os desafios para uma avaliação formativa na Pósgraduação. Avaliação, segundo Freitas (2014), "é uma categoria pedagógica polêmica. Diz respeito ao futuro. Portanto, mexe com a vida das pessoas, abre portas ou as fecha, submete ou desenvolve, enfim, é uma categoria permeada por contradiçóes" (FREITAS, 2014, p. 7). O adjetivo formativa traz desafios para compreender avaliação, principalmente quando se pensa em, através da avaliação, quantificar, medir, aferir e atribuir uma nota ou um conceito que altere, também, a vida de pessoas.

Compreendemos o adjetivo formativa, atribuído à avaliação, da mesma maneira que compreendemos o verbo formar. Formar, em nossa concepçáo, é formar-se, constituir-se, criar-se e recriar-se a partir dos encontros com o mundo. Assim, para que haja formação, necessário se faz que nos encontremos com o 
mundo. Concebemos encontro a partir do conceito criado pelo filósofo francês Gilles Deleuze (2002), com inspiraçóes em Espinosa. Deleuze concebe o encontro como potência para constituir subjetividades. A grande questão de Espinosa, que passa a ser também a grande questão de Deleuze (DELEUZE; PARNET, 1998), O que pode um corpo? De que afetos você é capaz?, movimenta-se a partir do pensamento de que é só no encontro que o corpo aumenta ou diminui sua potência de agir. É na intersecção dos afectos $^{4}$ que a formação acontece. Para o francês, existem encontros felizes e tristes. Os felizes aumentam nossa potência de agir, nos fortalecem. Os tristes nos enfraquecem, diminuem nossas forças, nos despotencializam. Mas ambos os encontros fazem algo com nosso corpo. Modificam-nos. Ambos são encontros formativos.

Os encontros do Seu Neca, com o projeto de pesquisa e inserção social acima narrado, o afetaram de tal forma que ele se tornou outro. Ele só, não, a sua comunidade também. Nota-se que o projeto também foi afetado pela experiência desses encontros. $\mathrm{O}$ projeto potencializou e foi potencializado pelos encontros. Ambos se formaram, ambos se trans-formaram. Mas essa experiência formativa, pela pesquisa, interessa a quem? Como publicar melhor se determinados discursos não cabem em revistas qualificadas?

Eis o nosso desafio: potencializar encontros entre as pesquisas imanentes, acontecimentos, desenvolvidas por pesquisadores sujos de mundo, com a Plataforma Sucupira. Seria possível mudar a Plataforma e fazê-la sujar-se, sentir as dores e as delícias do mundo? Seria possível aumentar o percentual avaliado a partir de narrativas como essas? Como?

Bem, não temos respostas a essas difíceis questôes. Talvez narrando essas questóes e problematizando-as na parte descritiva da Plataforma Sucupira, mais do que apresentando apenas o que a Plataforma requer, possamos propiciar um encontro que produza efeitos de avaliação formativa neste novo quadriênio (20172020). Talvez consigamos, narrando, cantando, descrevendo, fotografando, questionando, compondo, criar encontros que propiciem sensibilidades éticas, políticas e estéticas na avaliação de Programas de Pós-Graduação em Educação. Talvez assim consigamos divinar, também, na Sucupira e traduzir os $15 \%$ atualmente atribuídos na ficha de avaliação à Inserção Social em um maior peso para Programas que fazem diferença em suas comunidades. Para além da internacionalização... divinalização, é isso que propomos como Avaliação Formativa na Pós-Graduação.

4 Para Espinosa os afectos são as modificaçōes de corpos a partir dos efeitos produzidos nas relaçōes de um corpo sobre o outro (DELEUZE, 2002). 


\section{Referências}

BAPTISTA, Luis Antonio e SILVA, Rodrigo Lara. A cidade dos anjos do improrrogável. Revista Polis e Psique, 2017; 7 (1): $49-73$.

BARROS, Manoel. Livro sobre Nada. 3a Ed., Rio de Janeiro/São Paulo: Record Editora, 1999.

BRASIL, Documento de Área - Educação. MEC/CAPES, 2016.

DELEUZE, Gilles. Diferença e Repetição. Tradução Luis Orlandi, Roberto Machado. Rio de Janeiro: Graal, 1988.

Espinosa: Filosofia prática.. Tradução de: Daniel Lins e Fabien Pascal Lins. São Paulo: Escuta, 2002.

DELEUZE, Gilles e PARNET, Claire. Diálogos. Tradução de Eloisa Araújo Ribeiro. - São Paulo: Editora Escuta, 1998.

FOUCAULT, Michel. A ordem do discurso. 5a ed. São Paulo: Ediçôes Loyola, 1999.

A verdade e as formas jurídicas. $3^{a}$ Ed., Rio de Janeiro: NAU Editora, 2005.

FREITAS. Luiz Carlos... [et. Al.] Avaliaçáo educacional: caminhando pela contramáo. $6^{a}$ ed. Petrópolis, RJ: Vozes, 2014.

GAGNEBIN, Jeanne Marie. Walter Benjamin: os cacos da história. 2 ed. São Paulo: Brasiliense, 1993.

LARROSA, Jorge. Linguagem e Educação depois de Babel. Belo Horizonte: Autêntica, 2004. 